\title{
Implementation of Nursing Process and Its Association with Working Environment and Knowledge in Ethiopia: A Systematic Review and Meta-Analysis
}

\author{
Wondimeneh Shibabaw Shiferaw (D), Tadesse Yirga Akalu, Abate Dargie Wubetu, \\ and Yared Asmare Aynalem (iD)
}

Department of Nursing, College of Health Science, Debre Berhan University, Debre Berhan, Ethiopia

Correspondence should be addressed to Wondimeneh Shibabaw Shiferaw; wshibabaw21@gmail.com

Received 9 December 2019; Revised 8 June 2020; Accepted 30 June 2020; Published 18 July 2020

Academic Editor: Maria H. F. Grypdonck

Copyright (C) 2020 Wondimeneh Shibabaw Shiferaw et al. This is an open access article distributed under the Creative Commons Attribution License, which permits unrestricted use, distribution, and reproduction in any medium, provided the original work is properly cited.

\begin{abstract}
Background. The nursing process is a scientific problem-solving approach, which directs nursing care and potentially improves quality of health care service. The national pooled implementation of the nursing process in Ethiopia remains unknown. Hence, this review and meta-analysis aimed to estimate the overall implementation of the nursing process and its association with the working environment and knowledge in Ethiopia. Methods. PubMed, Scopus, Cochrane Library, Google Scholar, PsycINFO, and CINAHL were searched and complemented by manual searches. The DerSimonian and Laird random effects model was applied to estimate the pooled effect size, odds ratios, and 95\% confidence interval across studies. The $I^{2}$ statistic was used to check heterogeneity between the studies. Sensitivity analysis was deployed to see the effect of a single study on the overall estimation. Publication bias was examined using funnel plot and Egger's regression test statistic. Analysis was performed using STATA ${ }^{\mathrm{TM}}$ Version 14 software. Results. Seven studies comprised of 1,268 study participants were included in this meta-analysis. The estimated pooled implementation of the nursing process in Ethiopia was $42.44 \%$ (95\% CI: $36.91,47.97 \%$ ). Based on subgroup analysis, methods of outcome measurement showed that the highest overall implementation of the nursing process was observed from studies conducted using self-report technique 42.95\% (95\% CI: 35.76, 50.15). Nurses working in stressful environment were $81 \%$ less likely to implement the nursing process (OR 0.19, 95\% CI: 0.04, 0.76), and nurses having good knowledge were 8 times more likely to implement nursing process (OR 8.38,95\% CI: 2.82, 24.86). Conclusion. The overall implementation of the nursing process in Ethiopia was relatively low. Good knowledge of nurse had paramount benefits to improve implementation of the nursing process. Therefore, nurse can be educated on the imperative of knowledge in order to enhance the nursing process implementation and to improve the overall quality of healthcare services. Furthermore, policymakers and other concerned bodies should give special attention to improving the implementation of the nursing process.
\end{abstract}

\section{Background}

Nursing is a dynamic profession with a unique perspective on people, environment, and health [1]. The nursing process is a systematic problem-solving approach used to identify, prevent, and treat actual or potential health problems and promote wellness. It consists of five steps: assessment, diagnosis, planning, implementation, and evaluation [2]. The use of the nursing process helps in making and planning a clear and effective nursing care that potentiates improvement of the quality of patient care [3]. Implementation of the nursing process in clinical settings facilitates high quality nursing care, improves client health outcomes, and promotes nursing as a professional scientific discipline [4]. In addition, studies claim that, by implementing the nursing process, the nursing profession will be strengthened, internationalized, and dignified as efforts to achieve patient care criteria [5]. The approach of client care has moved from the medical to a holistic care model [1]. The nursing process, in its emphasis on patient-centred and 
goal-oriented care, has the potential to improve the quality of nursing care and to meet individualized health care needs [6-10].

Emphasis on holistic patient care within the nursing process is key to delivering quality nursing practice and central to nursing education [11]. Standard implementation of the nursing process could improve quality of care and encourages the utilization of evidence-based nursing practice $[12,13]$. Appropriately implemented, the nursing process may provide meaning and relevance to professional knowledge [5]. Globally, the nursing process is recognized as an integral part of nursing education, practice, dynamic client care, and critical thinking in attempting to address the needs of clients [14]. The nursing process is the corner stone of the nursing profession $[15,16]$. Using the nursing process as a tool to guide nursing care allows nurses to make independent and evidence-informed decisions that can encourage healing [17].

Utilization of the nursing process could assure nurses that they are meeting their responsibility for the patient care and enable evaluation of nursing care quality [18]. The essence of the nursing process lies in benefits to the client and nursing profession [19]. The nursing process guides nursing activities, promotes quality of care, and provides professional autonomy [20]. Substantial variations on the implementation of the nursing process across the globe have been reported. For instance, it has been reported $33.1 \%$ in Kenya [10], 57.1\% in Nigeria [1], and $81.77 \%$ in Brazil [21]. On the other hand, a study conducted in the Democratic Republic of Congo showed that there was no implementation of the nursing process [22].

Factors that affect the implementation of the nursing process are complex and rooted in multiple factors. A review of several studies suggests that factors responsible to reduce the implementation of the nursing process include sociodemographic of nurses [10, 20, 22-29], patient-related factors $[26,28]$, knowledge and attitude of nurses [22, 26, 30, 31], and organizational factors $[14,23,25,29,30]$. On the other hand, a study conducted in Nigeria showed that institutional factors do not pose a barrier to the utilization of the nursing process $[4,32]$. Identification of associated factors can be used as benchmarks to design appropriate measures, to improve client safety, and enhance utilization of resources.

Ethiopian Federal Ministry of Health has been engaged in improving quality of nursing care across the country in the last five years. Among these, national nursing process guideline was developed, national nursing mobilization activities were conducted, national dressing code guideline was launched, and national nursing service quality improvement audit tools were developed [33]. Nursing process is incorporated as the part of the curriculum to both in private and government education sector in Ethiopia. Though the government of Ethiopia gives emphasis on quality of healthcare service and nursing care. Nurses are paid 1500-2400 USD per year, and there is no retention strategies in most Ethiopian health institutions with high nurse turn over being a common challenge in the country. The nurse to patient ratio ranges from $1: 6$ to $1: 12$ based on the individual institution patient load and nurse availability.
Despite the effort of Ethiopian Federal Ministry of Health since 2011 to prepare and distribute protocol to the implementation of nursing process for all health care settings [34], the implementation of the nursing process in different health care setting is not well developed and organized [4, 26, 35]. In Ethiopia, nurses constitute the backbone of healthcare delivery system to improve the quality of health care service, and implementation of the nursing process may contribute a significant role. Different primary studies in Ethiopia [24-27] show the implementation of the nursing process as significant and a major issue in nursing care. However, variation was observed among these studies. Therefore, this study aimed to estimate the overall implementation of the nursing process and its association with the working environment and nursing knowledge in Ethiopia. Findings from the current study could serve as benchmark for institutional health care policymakers to implement appropriate measures to improve the implementation of the nursing process.

1.1. Research Questions. Three research questions were posited for this study:

(1) What is the prevalence of implementation of the nursing process in Ethiopia?

(2) What is the association between implementation of the nursing process and knowledge on nursing process?

(3) What is the association between implementation of the nursing process and nurses' working environments?

\section{Methods}

2.1. Design and Search Strategy. To extract all relevant literature, electronic databases such as PubMed, Cochrane Library, Google Scholar, CINAHL, Cochrane Library, and Scopus were searched. In addition, a manual search of grey literature available on local university shelves, institutional repositories, and reference lists of all retrieved articles was conducted to identify additional relevant research to augment our meta-analysis. This search involved articles published from inception to April 1, 2019. The searches were restricted to full texts, free articles, human studies, and English language publications. Endnote X 8.1 reference manager software was used to collect and organize search outcomes and for removal of duplicate articles. The search strategy was developed using the Population Exposure Controls Outcome and Study design (PECOS) searching guide. The search was conducted using the following $\mathrm{MeSH}$ and free-text terms: "nursing process", "implementation", "nursing process implementation", and "Ethiopia". Boolean operators such as "AND" and "OR" were used to combine search terms.

\subsection{PECOS Guide}

2.2.1. Population. All nurses working within health care settings for at least six months. 
2.2.2. Exposure. Nurses who have good knowledge on the nursing process and working within well-organized environments.

2.2.3. Controls. Nurses who have poor knowledge on the nursing process and working in stressful environments.

\subsubsection{Outcome. Implementation of the nursing process.}

\subsubsection{Study Design. All observational studies.}

2.3. Eligibility Criteria. Studies were included if they met the following criteria: (1) articles conducted in Ethiopia; (2) articles published in peer reviewed journals and grey literature; (3) published in English language from inception to 2019; and (4) observational studies, reporting their outcome variable as implementation of the nursing process. Studies were excluded on any one of the following conditions: (1) not fully accessible (i.e., full text) at the time of our search process; (2) poor quality score as per the stated criteria; (3) duplicated citation; and (4) failure to measure the desired outcome (implementation of the nursing process).

2.4. Outcome of Interest. The main outcome of interest was the overall implementation of the nursing process. In the present review, implementation of the nursing process was evaluated either through nurse documentation of all its components from patient files or from the self-report of nurses working in a hospital or outpatient unit, in all of the following phases: data collection, nursing diagnosis, prescription of nursing, and evaluation of nursing [24, 27, 35]. The associated variables included in this review were working environment (i.e., well-organized versus stressful) and knowledge on the nursing process (i.e., good knowledge versus poor knowledge).

2.5. Data Extraction and Quality Assessment. Data were extracted by two authors using a Microsoft ${ }^{\mathrm{TM}}$ Excel spread sheet. For each included article, we extracted data regarding the name(s) of the author(s), year of publication, study area/ region, health institution, study design, sample size, sampling technique, tool to measure the outcome, reported prevalence with its 95\% confidence interval (CI), and information regarding the associated factors. The quality of each included study was assessed using the Newcastle-Ottawa Scale (NOS) [36]. Studies were included in the analysis if they scored $\geq 5$ out of 10 points in three domains of modified NOS components for cross-sectional studies $[36,37]$. The point allocation of each domain included selection (5 points), comparability ( 2 points), and outcome assessment (3 points). Furthermore, quality assurance checks were independently performed by three authors. Any disagreements at the time of data abstraction were resolved by discussion and consensus (Supplementary File 1).
2.6. Assessment of Risk of Bias in Included Studies. The risk of bias tool for prevalence studies developed by Hoy and colleagues [38] was used to assess the risk of bias among included studies. The risk of bias within the selected articles was classified as either low, moderate, or high. On the other hand, the Quality in Prognosis Studies tool was used to assess the risk of bias for studies, which reported the factors associated with the implementation of nursing process [39]. Both authors carried out the risk of bias assessment of the included studies independently (Supplementary File 2).

2.7. Heterogeneity and Publication Bias. Cochran's Q chisquare statistics and the $I^{2}$ statistical test were conducted to assess the random variations between primary studies [40]. In this study, heterogeneity was interpreted as an $I^{2}$ value of $0 \%=$ no heterogeneity, $25 \%=$ low, $50 \%=$ moderate, and $75 \%=$ high [41]. In case of high heterogeneity, subgroup analysis, meta regression, and sensitivity analyses were run to identify possible moderators of this heterogeneity. Potential publication bias was assessed by visually inspecting funnel plots and objectively using the Egger bias test ( $p<0.05$ was considered as statistical significant publication bias) [42].

2.8. Statistical Analysis. To obtain the overall implementation of the nursing process, a meta-analysis using the random effects DerSimonian and Laird model was performed due to significant heterogeneity among studies $\left(I^{2}=74.1 \%\right.$, $p<0.001$ ) [43]. The pooled effect size (i.e., proportion and odds ratio (OR)) with a $95 \%$ confidence interval (CI)) was generated and presented using a forest plot. The metaanalysis was performed using the STATA ${ }^{\mathrm{TM}}$ Version 14 software [44]. Finally, for all analyses, $p<0.05$ was considered statistically significant.

2.9. Presentation and Reporting of Results. To estimate the overall implementation of the nursing process, the preferred reporting items for systematic reviews and meta-analyses (PRISMA) guideline was used [45]. The PRISMA checklist was used alongside the final review. The entire process of study screening, selection, and inclusion were depicted with the aid of a flow diagram. Quantitative data were presented through forest plots and summary tables.

\section{Results}

3.1. Search Results. The search strategy identified a total of 648 articles. About 643 studies were found from six international databases and the remaining 5 were through a manual search. The databases included PubMed (4), Scopus (83), PsycINFO (46), Cochrane Library (68), Google scholar (327), and CINAHL (115). Out of them, 239 duplicate records were identified and removed. Second, from the rest 409 impending article, 371 articles were excluded after reading of titles and abstracts based on the predefined eligibility criteria. Finally, 25 full text articles were read and assessed. Based on the predefined criteria and quality 
assessment, seven articles met eligibility for the review and were included in the final analysis (Figure 1).

3.2. Baseline Characteristic of the Included Studies. A total of seven studies with 1,268 study participants were included in this meta-analysis. The implementation of the nursing process was obtained from various regions across the country with two studies from Amharic region [26, 35], one each from Afar [24], Addis Ababa [25], Harare [28], Tigray [30], and Southern Nations, Nationalities, and People's Region (SNNPR) [27]. With respect to sample size, half the studies had fewer than 200 participants [24, 26, 27]. The highest implementation of the nursing process $(52.1 \%)$ was reported in a study conducted in Addis Ababa [25], whereas the lowest $(32.7 \%)$ was reported in a study conducted in SNNPR [27]. Regarding tools used to measure implementation of the nursing process, five studies [24-28] used self-report, and two studies [30,35] employed a document review method. All the included studies were cross-sectional by design and were conducted among nurses working in different clinical setting of Ethiopia. The quality score of each primary study, based on the Newcastle-Ottawa quality score assessment, was moderate to high for all seven articles assessed (Table 1).

3.3. Implementation of Nursing Process in Ethiopia. The result of this meta-analysis using the random effects model showed that the overall implementation of the nursing process in Ethiopia was $42.44 \%$ (95\% CI: 36.90, 47.97), with high significance of heterogeneity being observed $\left(I^{2}=74.1 \%\right.$; $p<0.001$ ) (Figure 2).

3.4. Subgroup Analysis. The presence of high significance heterogeneity among the primary studies requires the need to conduct subgroup analysis. As a result, to ascertain the sources of heterogeneity, we undertook a subgroup analysis using a type of outcome measure as the variable of interest. The finding of subgroup analysis using a type of outcome measure showed that the highest implementation of the nursing process was observed in studies conducted using self-reported methods $42.95 \%$ (95\% CI: 35.76, 50.15) (Figure 3).

3.5. Meta-Regression Analysis. To investigate the possible source of variation across the included studies, we performed meta-regression by using publication year, outcome measurement, and sample size as covariate of interest. However, the result of the meta-regression analysis showed that both covariates were not statistically significant for the presence of heterogeneity (Table 2).

3.6. Sensitivity Analysis. To evaluate the effect of an individual study on the pooled effect size, sensitivity analysis was conducted. Sensitivity analyses using the random effects model revealed that no single study influenced the overall implementation of nursing process (Figure 4).
3.7. Publication Bias. To identify the presence of publication bias, Egger's test was performed. The evidence from Egger's regression test showed no significant proof of publication bias $(p=0.349)$.

3.8. Association between Working Environment and Implementation of the Nursing Process. According to the current meta-analysis, those nurses working in a stressful environment were $81 \%$ less likely to implement the nursing process compared with nurses working in a well-organized environment $\left(\mathrm{AOR}=0.19 ; 95 \% \mathrm{CI}\right.$ : 0.04, 0.76, $\left.I^{2}=84.2 \%\right)$ (Figure 5). The evidence from Egger's regression test showed significant evidence of publication bias $(p=0.032)$.

3.9. Association between Knowledge and Implementation of the Nursing Process. Nurses with good knowledge were 8.38 times more likely to implement the nursing process compared with nurses having poor knowledge (AOR $=8.38 ; 95 \%$ CI: 2.82, 24.86) (Figure 6). The evidence from Egger's regression test showed that there was no publication bias $(p=0.182)$.

\section{Discussion}

The main objective of this systematic review and metaanalysis was to estimate the overall implementation of the nursing process and its association with working environment and knowledge in Ethiopia. In this meta-analysis, the national pooled implementation of the nursing process in Ethiopia was estimated to be $42.44 \%$ (95\% CI: 36.9, 47.9\%). This finding was higher than that in a study conducted in Kenya with $33.1 \%$ [10]. However, this result was substantially lower than studies conducted in Nigeria with $57.1 \%$ [1] and Brazil with $81.77 \%$ [21]. This variation could be justified by difference in awareness, knowledge, educational background among nurses, policy, and health system strategies. For instance, in Brazil, there is an initiative, which emphasizes awareness-raising and training of nursing professionals in hospitals and outpatient clinics related to the nursing process implementation [31].

The result of the subgroup analysis based on methods of outcome measurement showed that the highest overall implementation of the nursing process was observed in studies using self-report technique $42.95 \%$ (95\% CI: 35.76, $50.15)$. The present study revealed that nurses who had good knowledge of the nursing process were positively associated with implementation of the nursing process. This finding was supported by other studies conducted in developing and developed countries [46-49]. The possible explanation might be nurses who have theoretical knowledge on the nursing process could successfully promote quality of care to clients [20,50].

According to the present review, nurses working in stressful environments were nearly $81 \%$ less likely to implement the nursing process as compared with those who are working in a well-organized environment. This finding is in agreement with a study conducted in Egypt [29]. This may 


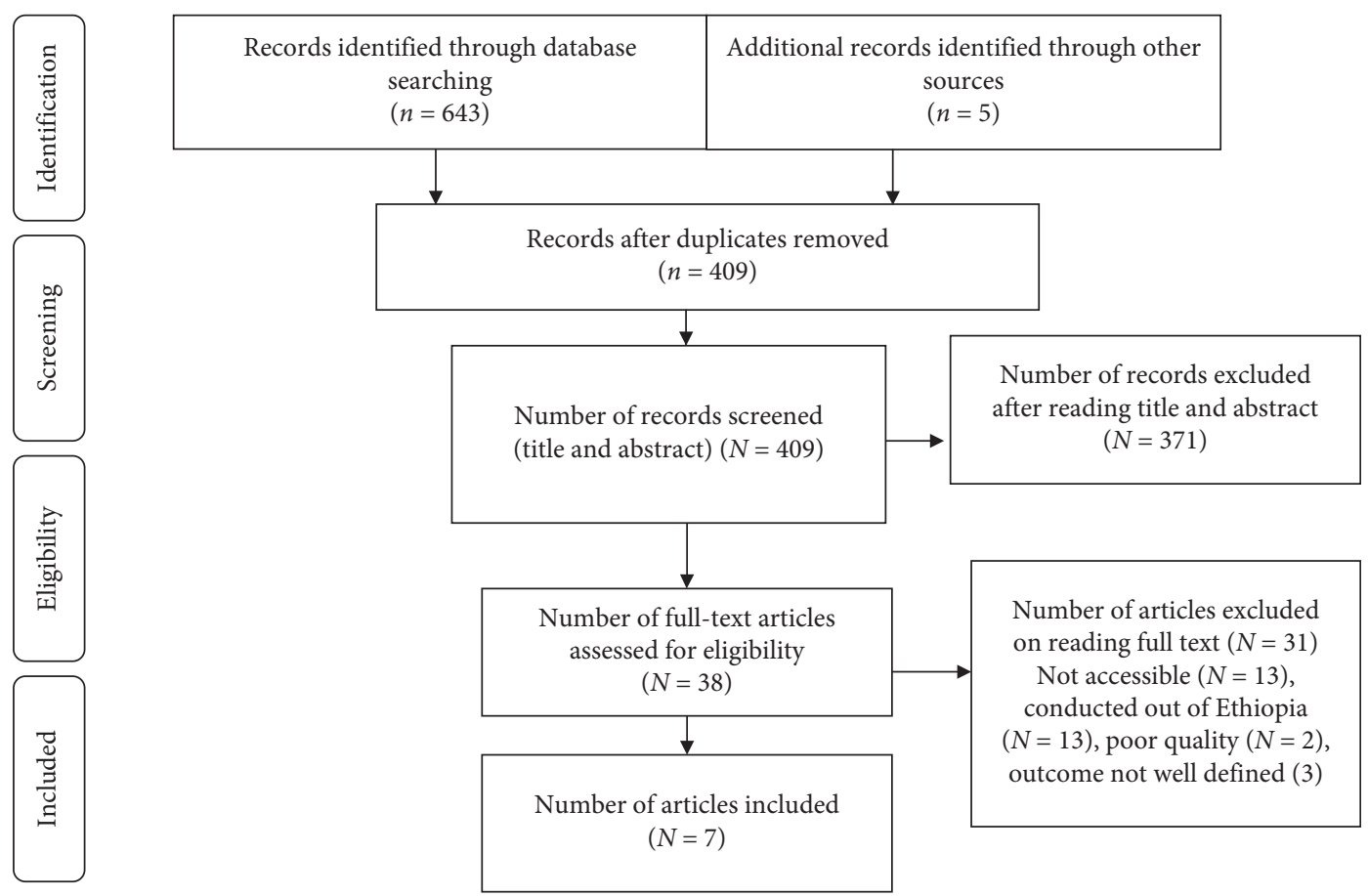

Figure 1: PRISMA flowchart diagram of the study selection.

TABLE 1: Baseline characteristics of studies included in the meta-analysis.

\begin{tabular}{|c|c|c|c|c|c|c|c|c|}
\hline Primary author & $\begin{array}{l}\text { Pub. } \\
\text { year }\end{array}$ & $\begin{array}{l}\text { Study area, } \\
\text { Region }\end{array}$ & Health facility name & Sampling & $\begin{array}{l}\text { Sample } \\
\text { size }\end{array}$ & $\begin{array}{l}\text { Prevalence \% } \\
\quad(95 \% \mathrm{CI})\end{array}$ & $\begin{array}{c}\text { Fool to measure } \\
\text { outcome } \\
\text { variable }\end{array}$ & $\begin{array}{l}\text { Quality } \\
\text { score }\end{array}$ \\
\hline Abebe et al. [26] & 2014 & Amhara & $\begin{array}{c}\text { Finoteselam and } \\
\text { Debre Markos } \\
\text { Hospital }\end{array}$ & Census & 139 & $37.1(28.6-45.6)$ & Self-reported & 6 \\
\hline $\begin{array}{l}\text { Miskir and } \\
\text { Emishaw et al. [24] }\end{array}$ & 2018 & Afar & Afar region hospitals & $\begin{array}{l}\text { Simple } \\
\text { random }\end{array}$ & 107 & $42.1(32.5-51.6)$ & Self-reported & 7 \\
\hline Aseratie et al. [25] & 2014 & $\begin{array}{l}\text { Addis } \\
\text { baba }\end{array}$ & Public hospitals & $\begin{array}{l}\text { Simple } \\
\text { random }\end{array}$ & 202 & $52.1(45.0-59.2)$ & Self-reported & 8 \\
\hline $\begin{array}{l}\text { Shewangizaw and } \\
\text { Mersha et al. [27] }\end{array}$ & 2015 & $\begin{array}{l}\text { Arba } \\
\text { Minch, } \\
\text { SNNPR }\end{array}$ & $\begin{array}{c}\text { Arba Minch General } \\
\text { Hospital }\end{array}$ & $\begin{array}{l}\text { Simple } \\
\text { random }\end{array}$ & 105 & $32.7(23.4-41.9)$ & Self-reported & 8 \\
\hline Baraki et al. [30] & 2017 & Tigray & $\begin{array}{l}\text { Hospitals of Central } \\
\text { and Northwest zones }\end{array}$ & $\begin{array}{l}\text { Simple } \\
\text { random }\end{array}$ & 200 & $35.0(28.4-41.6)$ & $\begin{array}{l}\text { Document } \\
\text { review }\end{array}$ & 7 \\
\hline Semachew [35] & 2018 & Amhara & $\begin{array}{c}\text { Felege Hiwot Referral } \\
\text { Hospital } \\
\text { Debretabor and } \\
\text { Finoteselam general } \\
\text { hospitals }\end{array}$ & $\begin{array}{l}\text { Systematic } \\
\text { random }\end{array}$ & 338 & $47.0(41.7-52.3)$ & $\begin{array}{l}\text { Document } \\
\text { review }\end{array}$ & 7 \\
\hline Atnafe et al. [28] & 2017 & Harare & $\begin{array}{c}\text { Public Hospitals of } \\
\text { Harari People } \\
\text { National Regional } \\
\text { State }\end{array}$ & $\begin{array}{l}\text { Systematic } \\
\text { random }\end{array}$ & 177 & $48.9(41.5-56.3)$ & Self-reported & 6 \\
\hline
\end{tabular}

reflect that a conducive environment is a necessary condition for effective and efficient nursing practice.

The meta-analysis conducted in this study has limitations that should be considered in future research. First, it is difficult to determine if the results from various regions are representative of the entire country, as no data were found for all regions of Ethiopia; second, most of the studies included had small sample size. Third, it was challenging to synthesise some of the factors as they were not defined or measured in the same way across the different studies; fourth, included studies only reported on hospital level data. Last, it was challenging to compare and contrast our findings with others because of lack of other published systematic review and meta-analysis on the implementation of the nursing process. 


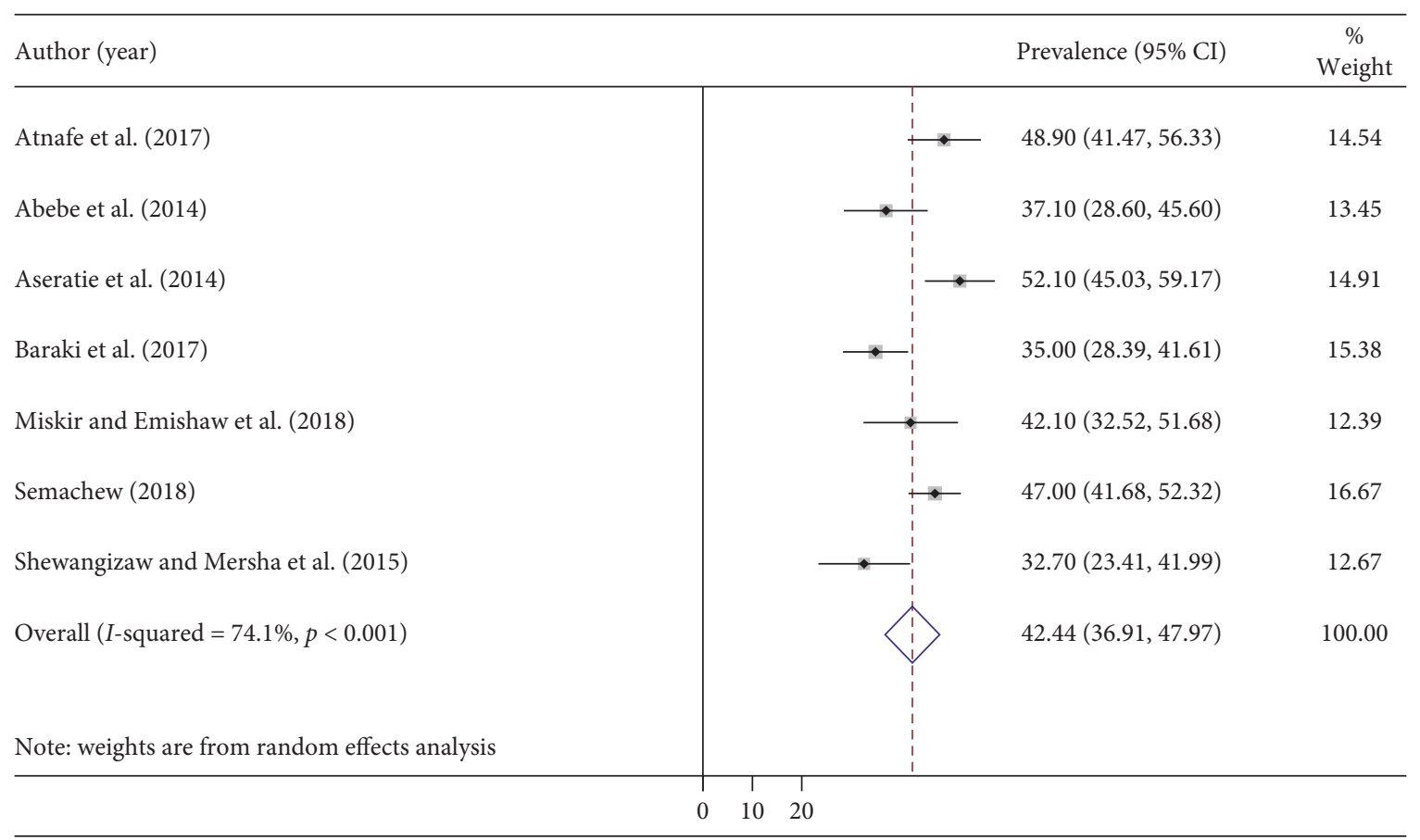

FIGURE 2: Forest plot showing the pooled prevalence of implementation nursing process.

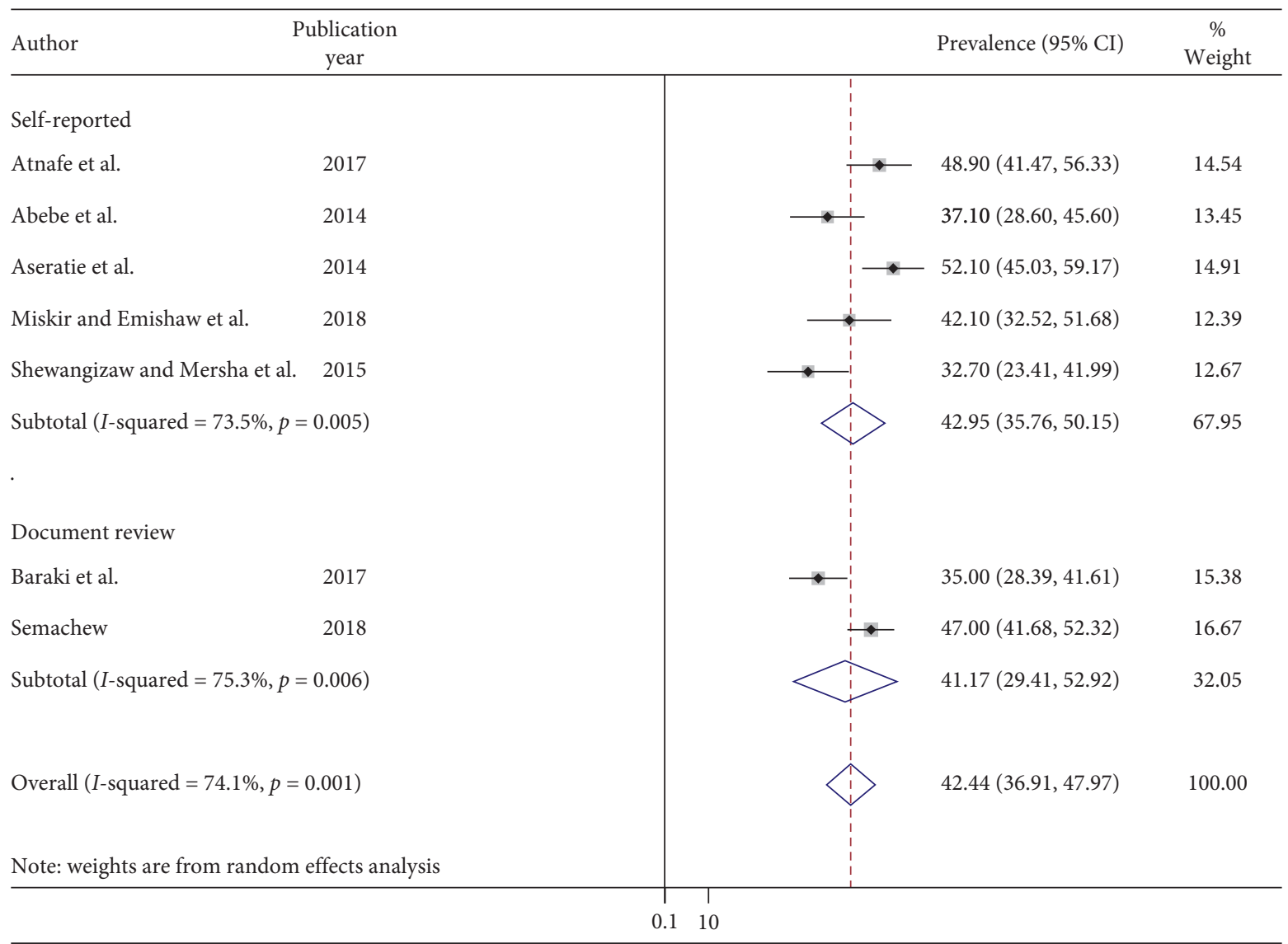

Figure 3: Subgroup analysis by methods of outcome measurement. 
TABLE 2: Meta regression analysis for the included studies to identify source of heterogeneity.

\begin{tabular}{|c|c|c|c|c|}
\hline Covariate (source) & Coefficients & Standard error & $p$ value & $95 \% \mathrm{CI}$ \\
\hline Publication year & -0.010 & 1.011 & 0.992 & $-6.062,5.131$ \\
\hline Sample size & 0.047 & 0.043 & 0.338 & $-0.073,0.168$ \\
\hline $\begin{array}{l}\text { Type of outcome measure } \\
\text { Self-report }\end{array}$ & 0.029 & 1.002 & 0.978 & $-2.546,2.605$ \\
\hline Document review (ref.) & & & & \\
\hline
\end{tabular}

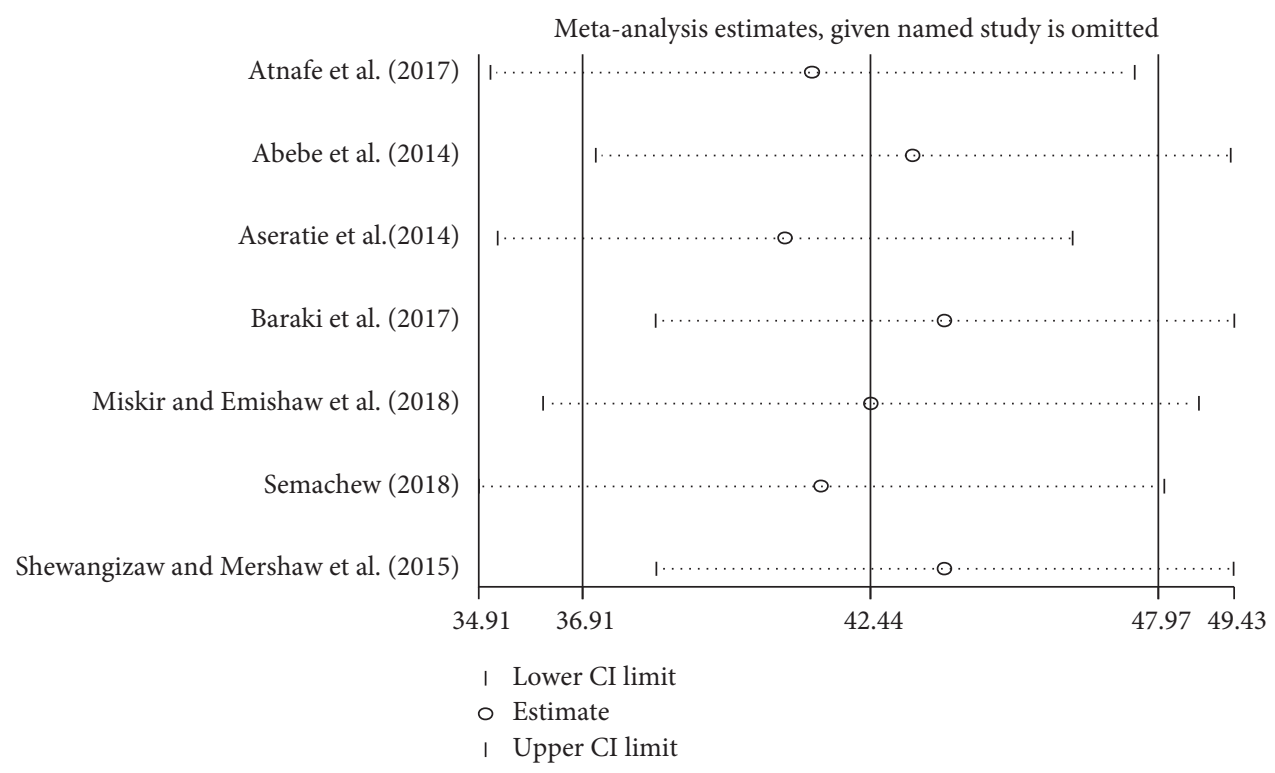

FIgURE 4: Result of sensitivity analysis of the seven studies.

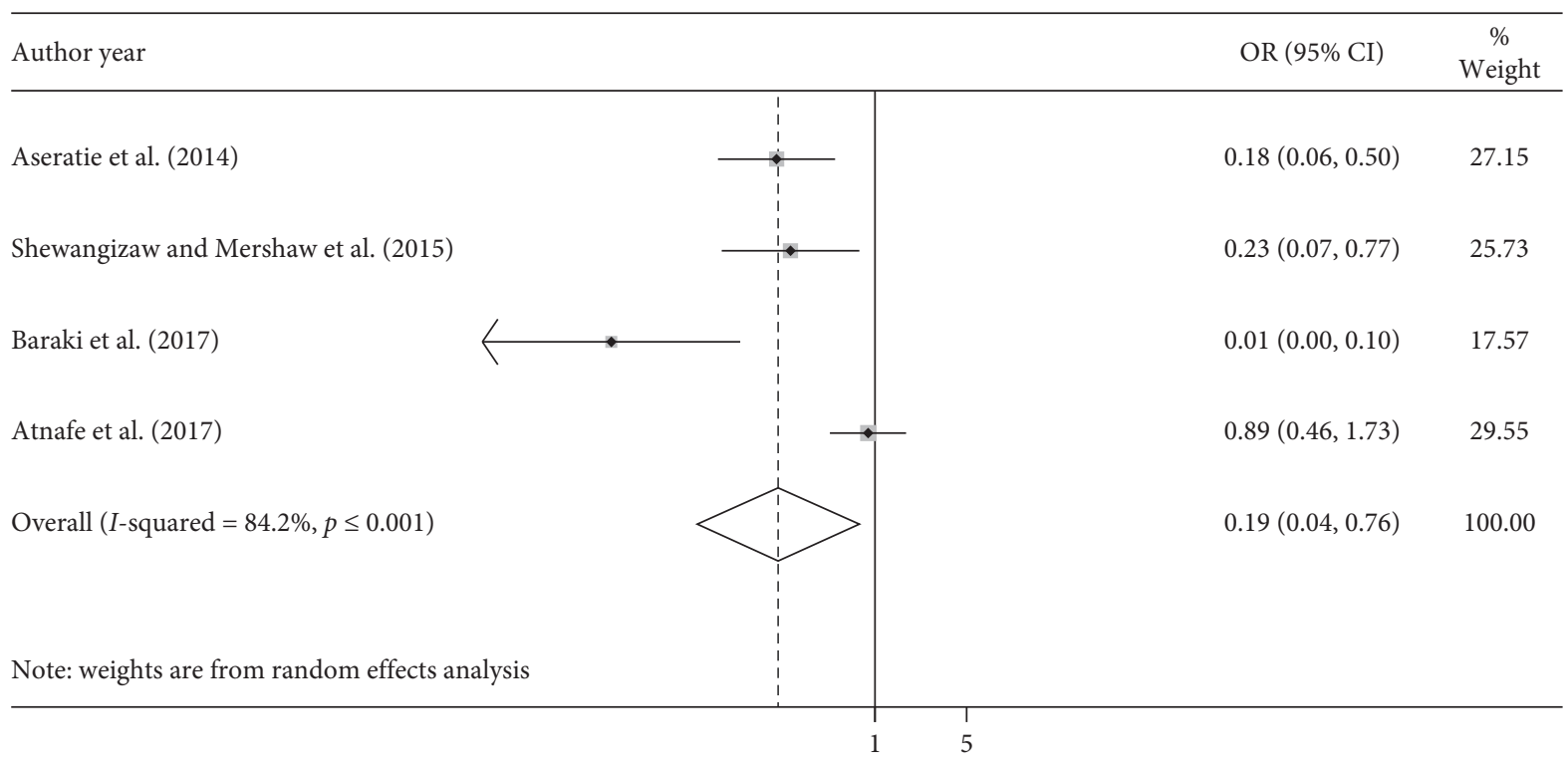

FIGURE 5: Forest plot showing the association between implementation of the nursing process and nurse working environment.

4.1. Implications for Nursing Practice. This meta-analysis has implications for clinical practice. Estimating the overall implementation of the nursing process would serve as a baseline for health care providers on the utilization of the nursing process, as standard of care, and to address client demand. The finding emphasizes the need for nursing educators to facilitate and encourage knowledge of the nursing process amongst their students in order to embed this practice. Furthermore, there is an imperative to design and implement different strategies on nursing knowledge and 


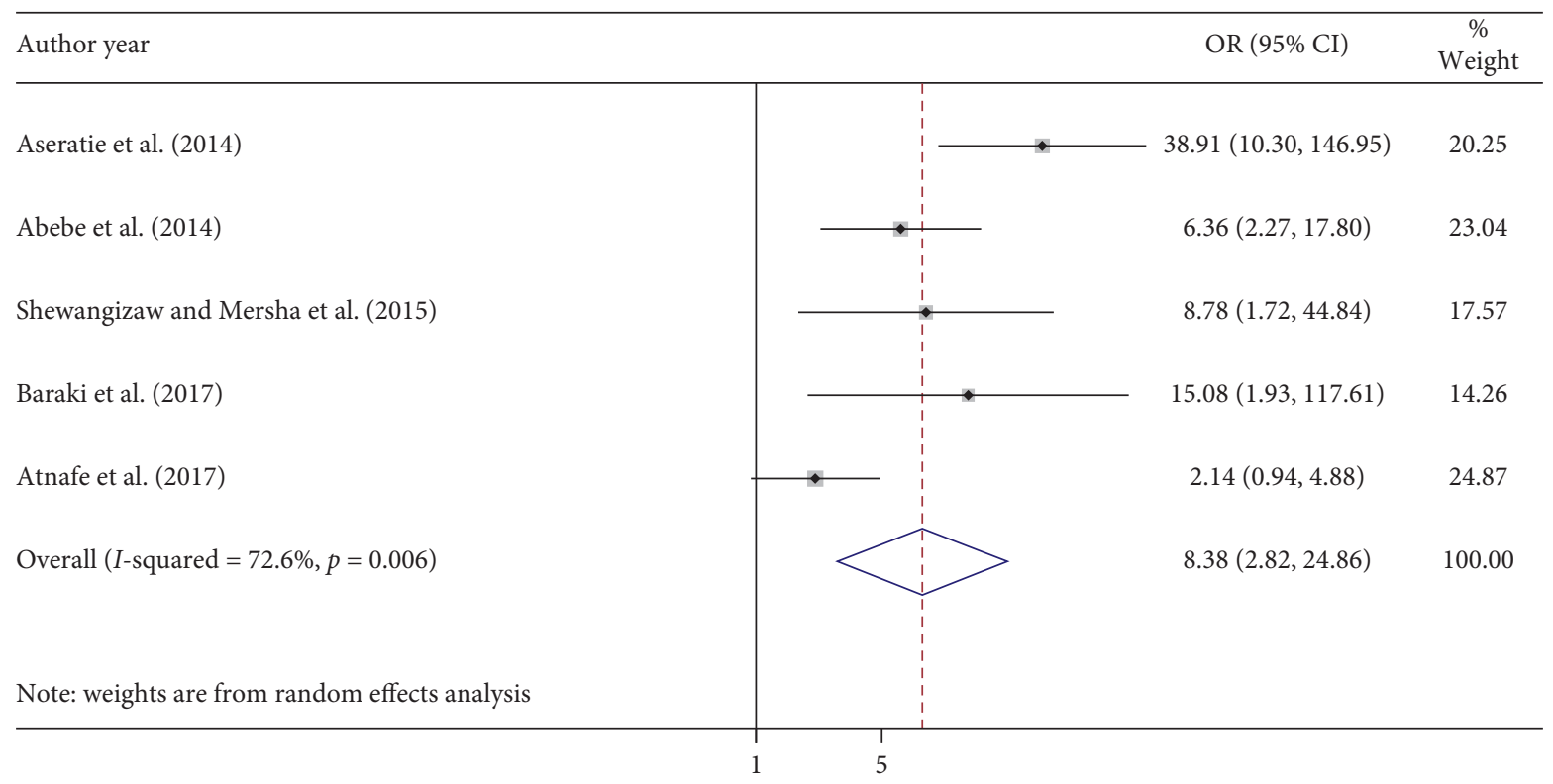

FIGURE 6: Forest plot shows the association between implementation of the nursing process and knowledge on nursing process.

working environment to enhance the potential implementation of the nursing process across the health care system.

\section{Conclusion and Recommendations}

The overall implementation of the nursing process in Ethiopia was relatively low. Good knowledge of the nurse had paramount benefits to improve implementation of the nursing process. Therefore, nurses can be educated on the imperative of knowledge in order to enhance the nursing process implementation and to improve the overall quality of healthcare services. Furthermore, policymakers (FMOH) and other concerned bodies should give special attention to improve implementation of the nursing process.

\section{Abbreviations}

CI: $\quad$ Confidence interval

FMOH: Federal ministry of health

OR: $\quad$ Odds ratio

PRISMA: Preferred reporting items for systematic reviews and meta-analyses

SNNP: Southern nations, nationalities, and peoples

WHO: $\quad$ World Health Organization.

\section{Data Availability}

The data used to support the findings of this study are included within the article.

\section{Disclosure}

This research was performed as part of the employment in Debre Berhan University.

\section{Conflicts of Interest}

The authors declare that they have no conflicts of interest.

\section{Authors' Contributions}

WSS and TYA developed the protocol; were involved in the design, selection of study, data extraction, and statistical analysis; and developed the initial drafts of the manuscript. YAA, ADW, and TYA involved in data extraction, quality assessment, statistical analysis, and revising subsequent drafts. WSS and YAA prepared the final draft of the manuscript. All authors read and approved the final draft of the manuscript.

\section{Supplementary Materials}

Supplementary file 1: methodological quality assessment of cross-sectional studies using the modified Newcastle-Ottawa Scale (NOS). Supplementary file 2: risk of bias tool for implementation of the nursing process and its association with working environment and knowledge in Ethiopia. (Supplementary Materials)

\section{References}

[1] B. Afoi, A. Emmanueul, S. Garba, S. Gimba, and V. Afuwai, "Evaluation of the implementation of nursing process among nurse clinicians," 2012.

[2] L. M. Huckabay, "Clinical reasoned judgment and the nursing process," in Nursing Forum, pp. 72-78, Wiley Online Library, New York, NY, USA, 2009.

[3] P. J. Potter and N. Frisch, "Holistic assessment and care: presence in the process," Nursing Clinics of North America, vol. 42, no. 2, pp. 213-228, 2007.

[4] F. Hagos, F. Alemseged, F. Balcha, S. Berhe, and A. Aregay, "Application of nursing process and its affecting factors 
among nurses working in Mekelle zone hospitals, northern Ethiopia," Nursing Research and Practice, vol. 42, 2014.

[5] J. Granero-Molina, C. Fernández-Sola, M. H. Peredo de Gonzales, G. Aguilera-Manrique, J. Mollinedo-Mallea, and A. M. Castro-Sánchez, "Proceso de enfermería: ¿qué significa para las enfermeras de Santa Cruz (Bolivia)?" Revista da Escola de Enfermagem da USP, vol. 46, no. 4, pp. 973-979, 2012.

[6] R. Alfaro-Lefevre, "Nursing process overview applying nursing process," Lippincott Wiliams \& Wilkins, Philadelphia, PA, USA, 2006.

[7] B. Yildirim and S. Ozkahraman, "Critical thinking in nursing process and education," International Journal of Humanities and Social Science, vol. 1, no. 13, pp. 257-262, 2011.

[8] American Nurses Association, "The nursing process: a common thread among all nurses," 2009.

[9] A. Berman, S. Shipton, and H. Walker, Fundamentals of Nursing: Concepts, Process and Practice, Benjamin-Cummings Publishing Company, Philadelphia, PA, USA, 2000.

[10] M. Kamau, N. Maingi, E. Ndungu, and J. Karonjo, Implementation of Nursing Process Among Nurses Working in InPatients Wards in Rift Valley Provincial General Hospital, Benjamin-Cummings Publishing, Nakuru County, Kenya, 2016.

[11] R. A. Mamseri, “The nursing process as a means of improving patient care," 2012.

[12] S. Pokorski, M. A. Moraes, R. Chiarelli, A. P. Costanzi, and E. R. Rabelo, "Nursing process: from literature to practice. What are we actually doing?" Revista Latino-Americana de Enfermagem, vol. 17, no. 3, pp. 302-307, 2009.

[13] M. Müller-Staub, I. Needham, M. Odenbreit, M. Ann Lavin, and T. Van Achterberg, "Improved quality of nursing documentation: results of a nursing diagnoses, interventions, and outcomes implementation study," International Journal of Nursing Terminologies and Classifications, vol. 18, no. 1, pp. 5-17, 2007.

[14] K. E. Siemuri, O. F. Oladayo, and N. Ugochukwu, "Factors influencing the utilization of the nursing process in Ogun State, Nigeria," International Journal of General Medicine and Pharmacy, vol. 2, no. 3, pp. 57-64, 2014.

[15] J. B. George, "Nursing theories: the base for professional nursing practice," Pearson Education India, vol. 6, 2011.

[16] B. Kozier, "Fundamentals of nursing: concepts, process, and practice: Pearson education," 2008.

[17] International Council of Nurses, "NewsCAP: the international council of nurses (ICN) updates its code of ethics," AJN, American Journal of Nursing, vol. 113, p. 15, 2013.

[18] T.-T. Lee, "Nursing diagnoses: factors affecting their use in charting standardized care plans," Journal of Clinical Nursing, vol. 14, no. 5, pp. 640-647, 2005.

[19] E. Sangster-Gormley, R. Martin-Misener, B. Downe-Wamboldt, and A. DiCenso, "Factors affecting nurse practitioner role implementation in Canadian practice settings: an integrative review," Journal of Advanced Nursing, vol. 67, no. 6, pp. 1178-1190, 2011.

[20] O. C. A. D. Queiroz, R. S. E. Sant'Ana, S. D. C. Oliveira, A. S. Moinhos, and L. S. Santos, "Nurse's perception in front of the implementation of nursing diagnosis and prescription," Journal of Nursing UFPE on Line, vol. 6, no. 6, pp. 1346-1351, 2012.

[21] O. A. d. Azevedo, É. d. S. Guedes, S. A. N. Araújo, M. M. Maia, and D. D. A. L. M. D. Cruz, "Documentação do processo de enfermagem em instituições públicas de saúde," Revista da Escola de Enfermagem da USP, vol. 53, 2019.
[22] N. K. Julie, I. K. Simon, K. U. Irène et al., "Barriers to the implementation of the nursing approach in public hospitals in lubumbashi in the democratic republic of Congo: a crosssectional descriptive study," OALib, vol. 4, no. 7, pp. 1-14, 2017.

[23] L. Souza, C. M. C. Capeline, A. L. Postigo, C. Vasconcellos, and A. V. Parra, "Knowledge production about nursing process: analysis of the difficulties during the period from 2003 to 2013," International Jorunal of Multidisciplinary Current Researrch, vol. 3, pp. 231-236, 2015.

[24] Y. Miskir and S. Emishaw, "Determinants of nursing process implementation in Northeast Ethiopia: cross-sectional study," Nursing Research and Practice, vol. 3, 2018.

[25] M. Aseratie, R. Murugan, and M. Molla, "Assessment of factors affecting implementation of nursing process among nurses in selected governmental hospitals, Addis Ababa, Ethiopia: a cross-sectional Study," Journal of Nursing Care, vol. 3, no. 3, p. 170, 2014.

[26] N. Abebe, H. Abera, and M. Ayana, "The implementation of nursing process and associated factors among nurses working in Debremarkos and Finoteselam Hospitals, Northwest Ethiopia, 2013," Journal of Nursing Care, vol. 2014, pp. 4-7, 2014.

[27] Z. Shewangizaw and A. Mersha, "Determinants towards implementation of nursing process," American Journal of Nursing Science, vol. 4, no. 3, pp. 45-49, 2015.

[28] G. T. Atnafe, B. Habte, and L. N. Negesa, "The practice of nursing process and associated factors among nurses working in public hospitals of harari people national," Regional State EE, vol. 32, 2017.

[29] M. H. B. H. Mahmoud, "Barriers and facilitators for execution of nursing process from nurses' perspective," International Journal of Advanced Research, vol. 2, no. 2, pp. 300-315, 2014.

[30] Z. Baraki, F. Girmay, K. Kidanu, H. Gerensea, D. Gezehgne, and H. Teklay, "A cross sectional study on nursing process implementation and associated factors among nurses working in selected hospitals of Central and Northwest zones, Tigray Region, Ethiopia," BMC Nursing, vol. 16, no. 1, p. 54, 2017.

[31] A. A. S. Bersusa, "Qualificando para a assistência de enfermagem: projeto "Tecendo a SAE em São Paulo"” BIS Boletim do Instituto de Saúde (Impresso), vol. 48, pp. 61-66, 2009.

[32] F. O. Adeyemo and A. Olaogun, "Factors affecting the use of the nursing process in health institutions in Ogbomoso town, Oyo State," International Journal of Medical Pharmacology Sciences, vol. 1, pp. 191-198, 2013.

[33] FMOH, "Health sector transformation plan- $i$ annual performance report 01," 2016.

[34] Federal Ministry of Health (FMOH), "Nursing care practice standards, ethiopia," 2011.

[35] A. Semachew, "Implementation of nursing process in clinical settings: the case of three governmental hospitals in Ethiopia, 2017," BMC Research Notes, vol. 11, no. 1, p. 173, 2018.

[36] P. A. Modesti, G. Reboldi, F. P. Cappuccio et al., "Panethnic differences in blood pressure in Europe: a systematic review and meta-analysis," PloS One, vol. 11, no. 1, 2016.

[37] K. G. Yazew, T. A. Walle, and A. W. Azagew, "Prevalence of antidiabetic medication adherence and determinant factors in Ethiopia: a systemic review and meta-analysis, 2019," International Journal of Africa Nursing Sciences, vol. 11, 2019.

[38] D. Hoy, P. Brooks, A. Woolf et al., "Assessing risk of bias in prevalence studies: modification of an existing tool and evidence of interrater agreement," Journal of Clinical Epidemiology, vol. 65, no. 9, pp. 934-939, 2012. 
[39] J. A. Hayden, D. A. van der Windt, J. L. Cartwright, P. Côté, and C. Bombardier, "Assessing bias in studies of prognostic factors," Annals of Internal Medicine, vol. 158, no. 4, pp. 280-286, 2013.

[40] T. B. Huedo-Medina, J. Sánchez-Meca, F. Marín-Martínez, and J. Botella, "Assessing heterogeneity in meta-analysis: $Q$ statistic or $I^{2}$ index?" Psychological Methods, vol. 11, no. 2, pp. 193-206, 2006.

[41] J. Higgins and S. Green, "Assessing risk of bias in included studies," Cochrane Handbook for Systematic Reviews of Interventions, vol. 2008, 2011.

[42] M. Egger, G. Davey-Smith, and D. Altman, Systematic Reviews in Health Care: Meta-Analysis in Context, John Wiley \& Sons, New York, NY, USA, 2008.

[43] M. Borenstein, L. V. Hedges, J. P. Higgins, and H. R. Rothstein, Introductionto Meta-Analysis, John Wiley \& Sons, England, UK, 2009.

[44] L. StataCorp, Stata Statistical Software (Version Release 14), John Wiley \& Sons, College Station, TX, USA, 2015.

[45] A. Liberati, D. G. Altman, J Tetzlaff et al., "The PRISMA statement for reporting systematic reviews and meta-analyses of studies that evaluate health care interventions: explanation and elaboration," PLoS Medicine, vol. 6, no. 7, 2009.

[46] L. P. C. C. Souza, A. L. Postigo, C. Vasconcellos, and A. V. Parra, "Knowledge production about nursing process: analysis of the difficulties during the period from 2003 to 2013," International Journal of Multidisciplinary Current Research, vol. 6, 2015.

[47] V. V. L. Zamanzadeh, F. J. Tabrizi, M. Behshid, and M. Lotfi, "Challenges associated with the implementation of the nursing process: a systematic review," Iranian Journal of Nursing and Midwifery Research, vol. 20, no. 4, p. 411, 2015.

[48] R. A. Mamseri, "The nursing process as a means of improving patient care," Master thesis, University of South Africa, London, UK, 2012.

[49] M. G. Fard, H. R. Haririan, A. Aghajanloo, M. Akbari, and Y. Shirvani, "Obstacles of nursing process application from perspective of the nursing instructor and nursing students in Zanjan faculty of nursing and midwifery," International Journal of Multidisciplinary Current Research, vol. 5, no. 8, pp. 69-77, 2012.

[50] H. Hasson and J. E. Arnetz, "The impact of an educational intervention on nursing staff ratings of quality of older people care: a prospective, controlled intervention study," International Journal of Nursing Studies, vol. 46, no. 4, pp. 470-478, 2009. 